\title{
Preparation, characterization and catalytic activity of amphiphilic cyclopalladated aryl imines and their Langmuir-Blodgett films
}

\author{
Na Zhao, Fei Wang, Meiling Zhou, Tiesheng Li \#, Hui Liu, Wenjian Xu, Yangjie Wu* \\ Key Laboratory of Chemical Biology and Organic Chemistry of Henan Province, Key Laboratory of Advanced Nano-information Materials, \\ College of Chemistry and Molecular Engineering, Zhengzhou University, Zhengzhou 450052, Henan, China
}

\section{A R T I C L E I N F O}

\section{Article history:}

Received 20 April 2013

Accepted 13 May 2013

Published 20 August 2013

Keywords:

Aryl imine

Cyclopalladated catalyst

Langmuir-Blodgett film

Suzuki reaction

Heck reaction

\begin{abstract}
A B S T R A C T
A series of novel amphiphilic cyclopalladated aryl imines were synthesized and characterized. These catalysts showed high activity for Heck and Suzuki reactions in homogeneous systems. Heterogeneous Langmuir-Blodgett films of the catalysts also demonstrated high catalytic activity for these coupling reactions.
\end{abstract}

(C) 2013, Dalian Institute of Chemical Physics, Chinese Academy of Sciences. Published by Elsevier B.V. All rights reserved.

\section{Introduction}

Palladium-catalyzed coupling reactions are an important method for generating $\mathrm{C}-\mathrm{C}$ bonds in organic synthesis. Palladium catalysts tolerate a wide range of functional groups, can be used in a small amount, and also have low toxicity [1-5]. However, traditional catalysts such as $\mathrm{PdCl}_{2}, \mathrm{Pd}(\mathrm{AcO})_{2}$, $\mathrm{Pd}\left(\mathrm{PPh}_{3}\right)_{4}, \mathrm{Pd}_{2}(\mathrm{dba})_{3}$, and $\mathrm{PdCl}_{2}\left(\mathrm{PPh}_{3}\right)_{2}$ have a number of drawbacks and limitations including air-sensitivity and high cost [6-8]. In recent decades, cyclopalladated complexes have been extensively studied because of their high activity in various types of coupling reactions, stability in the air, no need for ancillary ligands, and simple synthetic methods [9-13]. Beller et al. [14] first reported the use of cyclopalladated complexes as catalysts for Heck and Suzuki coupling reactions, and various palladacycles have been reported since. Ohff and Weissman et al. described good performance from orthopalladated imines and CN-palladacycles for Heck [15] and Suzuki [16] reactions, respectively. In our previous work, we have focused on cyclopalladated ferrocenyl imines for Heck, Suzuki, and Sonogashira coupling reactions, and for $\mathrm{C}-\mathrm{H}$ activation chemistry [17-20].

The Langmuir-Blodgett (LB) technique is a simple, low cost method for assembling layers with well-defined molecular orientation and control over thickness at the molecular level to reproducibly produce highly ordered molecular arrays. One advantage of LB films is that various experimental techniques can be used to study reaction mechanisms. Recently, amphiphilic transition metal catalysts on substrates for catalytic application were studied by LB technique and have generated considerable interest. Töllner et al. [21] reported the hydrogenation of carbon-oxygen double bonds catalyzed by active LB

\footnotetext{
*Corresponding author. E-mail: wyj@zzu.edu.cn

\# Corresponding author.E-mail: Its34@zzu.edu.cn

This work was supported by the National Natural Science Foundation of China (20973157) and the Research and Development Foundation of Zhengzhou (094SGZG23056).

DOI: 10.1016/S1872-2067(12)60613-5 | http://www.sciencedirect.com/science/journal/18722067 | Chin. J. Catal., Vol. 34, No. 8, August 2013
} 


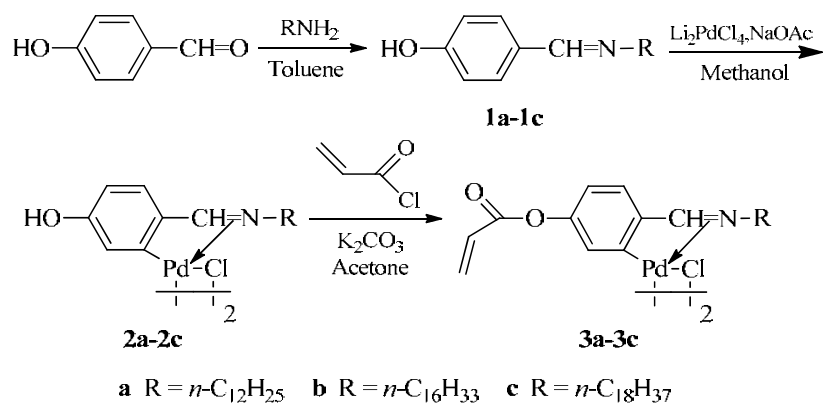

Scheme 1. Synthesis of arylimine cyclopalladated catalysts.

films of a rhodium complex. Abatti et al. [22] used porphyrin LB films as catalysts for alkene epoxidation, and doubled yields were obtained compared with the homogeneous system. Benítez et al. [23] investigated the catalytic properties of the zirconium phosphonate LB films and self-assembled monolayers using the epoxidation of cis-cyclooctene. Park et al. [24] reported catalytic $\mathrm{CO}$ oxidation by LB films of $\mathrm{Rh} / \mathrm{Pt}$ bimetallic nanoparticles.

In our previous studies, we synthesized a series of amphiphilic cyclopalladated ferrocenyl imines and investigated the activity of the LB films in Suzuki coupling reactions. However, the LB films presented with weak thermal stability and poor resistance to organic solvents, which prevented the investigation of the heterogeneous catalytic mechanism [25-27]. In order to overcome these limitations, a series of novel amphiphilic cyclopalladated arylimines (2a-2c and $\mathbf{3 a - 3 c}$, Scheme 1) were prepared and characterized. Their catalytic properties for Heck and Suzuki cross-coupling reactions were initially investigated in homogeneous systems to determine suitable experimental conditions for studies into heterogeneous catalytic activity of the self-assembled films. The catalyst 2b was found suitable for formation of monolayers and LB films on solid slides, and its catalytic activity in Suzuki coupling reactions was also investigated.

\section{Experimental}

\subsection{Synthesis of 4-[(alkyl imino)methyl)]phenol (1a-1c)}

A mixture of 4-hydroxybenzaldehyde (10 mmol), amine (10 mmol), $4 \AA$ molecular sieve ( $4 \mathrm{~g})$, and toluene $(150 \mathrm{ml})$ was refluxed under a nitrogen atmosphere at $115{ }^{\circ} \mathrm{C}$ for $7 \mathrm{~h}$. The reaction mixture was then filtered and a small amount of petroleum ether was added to the filtrate. The mixture was cooled and recrystallized at $0{ }^{\circ} \mathrm{C}$ to give the ligands $\mathbf{1 a - 1 c}$ as white crystals. The products were confirmed by ${ }^{1} \mathrm{H}$ NMR, ${ }^{13} \mathrm{C}$ NMR, and MS.

\subsection{Synthesis of $\left[\mathrm{PdCl}\left(\mathrm{HOC}_{6} \mathrm{H}_{6} \mathrm{CH}=\mathrm{NR}\right)\right]_{2}(\mathbf{2 a}-\mathbf{2 c})$}

A mixture of dilithium chloropalladate $(1.0 \mathrm{mmol})$, sodium acetate $(1.0 \mathrm{mmol}), \mathbf{1 a}-\mathbf{1 c}(1.1 \mathrm{mmol})$, and methanol $(10 \mathrm{ml})$ was stirred at room temperature for $24 \mathrm{~h}$. The mixture was then filtered, concentrated, and purified by silica column chro- matography using dichloromethane and methanol (6:1) to give compounds 2a-2c as yellow solids. The products were confirmed by ${ }^{1} \mathrm{H}$ NMR, ${ }^{13} \mathrm{C}$ NMR, and MS.

\subsection{Synthesis of $\left[\mathrm{PdCl}\left(\mathrm{CH}_{2}=\mathrm{CHC}=\mathrm{OC}_{6} \mathrm{H}_{6} \mathrm{CH}=\mathrm{NR}\right)\right]_{2}(3 \boldsymbol{a}-3 \boldsymbol{c})$}

A mixture of potassium carbonate $(3 \mathrm{~g}), \mathbf{2 a}-2 \mathrm{c}(1.0 \mathrm{mmol})$, and dichloromethane $(80 \mathrm{ml})$ was cooled by an ice bath under the nitrogen with stirring, and acryloyl chloride (1.2 mmol) was added. The resulting mixture was stirred on ice for a further 2 h. The ice bath was removed and the mixture was stirred at room temperature for $4 \mathrm{~h}$. A NaOH solution was added and the mixture was stirred for a further $30 \mathrm{~min}$. The mixture was then filtered, concentrated, and purified by silica column chromatography using dichloromethane and methanol (10:1) to give compounds $\mathbf{3 a - 3 c}$ as light yellow solids. The products were confirmed by ${ }^{1} \mathrm{H}$ NMR, ${ }^{13} \mathrm{C}$ NMR, and MS.

\subsection{Preparation of the Langmuir monolayer and LB films}

Chloroform solutions of the complexes were carefully spread onto an ultrapure water surface. After evaporation of solvent (30 $\mathrm{min})$ and stabilization of the films for $1 \mathrm{~h}$, the so formed Langmuir monolayers were compressed at a speed of 5 $\mathrm{mm} / \mathrm{min}$ at $20 \pm 1{ }^{\circ} \mathrm{C}$. LB films were transferred onto silicon slides and glass slides (for atomic force microscopy (AFM) and catalytic studies). The solid slides were cleaned in a boiling mixture of concentrated $\mathrm{H}_{2} \mathrm{SO}_{4}$ and concentrated $\mathrm{HNO}_{3}$ (1:1) for $1 \mathrm{~h}$ and then washed with pure water.

\subsection{Heck cross-coupling reactions}

Aryl halide $(0.5 \mathrm{mmol})$, styrene $(1.5 \mathrm{mmol})$, and catalyst 3a-3c (0.1 mol\%) were combined with $\mathrm{K}_{3} \mathrm{PO}_{4}(1.0 \mathrm{mmol})$ and dimethylformamide $(1.5 \mathrm{ml})$ or deionized water $(1.5 \mathrm{ml})$ in a small round-bottom flask. The reaction mixture was stirred and then quenched. The organic layer was separated and the aqueous layer was extracted with ethyl acetate three times. The organic phases were combined, dried with $\mathrm{MgSO}_{4}$, and filtered, and the resulting solution was analyzed by gas chromatography.

\subsection{Suzuki cross-coupling reactions}

Aryl halide ( $0.25 \mathrm{mmol})$, aryl boronic acid ( $0.60 \mathrm{mmol})$, catalyst 3a-3c (0.001 mol\%), and tetra- $n$-butylammonium bromide (TBAB, $0.30 \mathrm{mmol}$ ) were combined with $\mathrm{K}_{2} \mathrm{CO}_{3}(0.3$ mmol) and deionized water ( $1.5 \mathrm{ml})$ in a small round-bottom flask. The reaction mixture was stirred and then extracted with ethyl acetate three times. The organic phases were combined, dried with $\mathrm{MgSO}_{4}$, and filtered, and the resulting solution was analyzed by gas chromatography.

\section{Results and discussion}

\subsection{Catalytic properties for the homogeneous Heck coupling of} bromobenzene and styrene 
An initial survey of bases, including $\mathrm{Et}_{3} \mathrm{~N}, \mathrm{Na}_{2} \mathrm{CO}_{3}, \mathrm{~K}_{2} \mathrm{CO}_{3}$, $\mathrm{NaHCO}_{3}, \mathrm{NaOAc}, \mathrm{K}_{3} \mathrm{PO}_{4}$, and $\mathrm{K}_{3} \mathrm{PO}_{4} \cdot 3 \mathrm{H}_{2} \mathrm{O}$, used for Suzuki reaction of bromobenzene and styrene using $0.1 \mathrm{~mol} \%$ of catalyst 2b was investigated, and $\mathrm{K}_{3} \mathrm{PO}_{4}$ was found to give the best result ( $>99 \%$ conversion determined by GC). From the experiments, it was found that $100{ }^{\circ} \mathrm{C}$ was the optimal reaction temperature, and using dimethylformamide as the solvent gave the best conversion. Using dimethylformamide as solvent, $\mathrm{K}_{3} \mathrm{PO}_{4}$ as base, and TBAB as co-catalyst at $100{ }^{\circ} \mathrm{C}$, the activity of the catalysts for the Heck coupling of bromobenzene and styrene was investigated. The results are listed in Table 1.

Table 1 shows that all the catalysts gave high activity for this coupling reaction with $0.1 \mathrm{~mol} \%$ catalyst loading. Using catalyst $\mathbf{2 b}$, the cross-coupling of different kinds of aryl halides with styrene was shown to be efficient under the optimized reaction conditions. The results in Table 2 show that various substituted aryl bromides gave high yields of coupled products (entries 1-7). A number of heteroaromatic substrates such as bromonaphthalene also gave high conversion (entries 8-10).

To investigate the capability of the catalysts for other cross-coupling reactions, the Suzuki cross-coupling reaction of 4-bromotoluene $(0.5 \mathrm{mmol})$ and phenylboronic acid $(0.6$ mmol) was carried out with various bases and solvents in the presence of $0.001 \mathrm{~mol} \%$ of $\mathbf{2} \mathbf{b}$ without a blanket of inert gas. The reaction proceeded in ethanol-water solutions $(2: 1,3 \mathrm{ml})$ with $>99 \%$ conversion determined by GC. While several bases are suitable for this reaction, $\mathrm{NaOH}$ was chosen for its low cost Using these conditions, the relative activity of several palladacycles $\mathbf{2 a - 2} \mathbf{c}$ and $\mathbf{3 a - 3} \mathbf{c}$ for the same model reaction was then studied. As shown in Table 3. 2a and $\mathbf{2 b}$ showed good activity toward the reaction and were chosen for further investigation.

Using the same protocol and $0.001 \mathrm{~mol} \%$ loading of catalyst 2b, a variety of aryl bromides were able to be coupled efficiently with phenylboronic acid. The results are shown in Table 4. For activated and inactivated aryl bromides, excellent yields were obtained (entries 1-5 and 8-11). 1-Bromonaphthalene and 3-bromopyridine also exhibited high conversion of $97 \%$ and 77\%, respectively (entries 6 and 7). The amphiphilic cyclopalladated aryl imines were found to be efficient catalysts for Suzuki coupling of aryl bromides with phenylboronic acid.

Table 1

The relative activity of the catalysts on the Heck coupling of bromobenzene and styrene.

\begin{tabular}{lcc}
\hline Catalyst & Catalyst $/ \mathrm{K}_{3} \mathrm{PO}_{4}$ \\
\hline Entry & 2a & Yield ${ }_{4}$ (\%) \\
\hline 1 & $\mathbf{2 b}$ & $>99$ \\
2 & $\mathbf{2 c}$ & $>99$ \\
3 & 3a & $>99$ \\
4 & 3b & 98 \\
5 & 3c & 97 \\
6 & (E-only)
\end{tabular}

Reaction conditions: $\mathrm{PhBr} 0.5 \mathrm{mmol}$, styrene $1.0 \mathrm{mmol}$, catalyst 0.1 mol\%, $\mathrm{K}_{3} \mathrm{PO}_{4} 1.0 \mathrm{mmol}, n$-Bu $4 \mathrm{NBr} 0.5 \mathrm{mmol}, \mathrm{DMF} 2 \mathrm{ml}, 6 \mathrm{~h}$

a Determined by GC based on the products.
Table 2

Heck coupling of aryl halides with styrene using $\mathbf{2} \mathbf{b}$ as a catalyst.

Aryl halide

Reaction conditions: aryl halide $0.5 \mathrm{mmol}$, styrene $1.0 \mathrm{mmol}$, catalyst $0.1 \mathrm{~mol} \%$, base $1.0 \mathrm{mmol}, n$-Bu $\mathrm{NBr} 0.5 \mathrm{mmol}$, DMF $2 \mathrm{ml}, 6 \mathrm{~h}, 100{ }^{\circ} \mathrm{C}$.

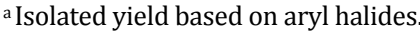

Table 3

The relative activity of the catalysts for the Suzuki coupling of 4-bromotoluene and phenylboronic acid.

\begin{tabular}{lcc} 
Catalyst & Yield $^{\mathrm{a}}(\%)$ \\
\hline Entry & $\mathbf{2 a}$ & $>99$ \\
$\mathbf{2 b}$ & $>99$ \\
2 & $\mathbf{2 c}$ & 87 \\
3 & $\mathbf{3 a}$ & 93 \\
4 & $\mathbf{3 b}$ & 93 \\
5 & $\mathbf{3 c}$ & 92 \\
6 & Solvent, $\mathrm{rt}$ \\
\hline Reaction conditions: 4-bromotoluene $0.5 \mathrm{mmol}, \mathrm{PhB}(\mathrm{OH})_{2}$ & $0.6 \mathrm{mmol}$, \\
NaOH 1.0 mmol, catalyst 0.001 mol\%, ethanol-water $(2: 1) 3 \mathrm{ml}, 8 \mathrm{~h}, \mathrm{rt}$.
\end{tabular}

\subsection{Amphiphilic cyclopalladated arylimines LB films for Suzuki coupling reaction}

LB films of compounds $\mathbf{2 a - 2 c}$ and $\mathbf{3 a - 3 c}$ were prepared, and their catalytic performance in Suzuki coupling reactions was investigated in heterogeneous systems. Compounds 2a-2c and $\mathbf{3 a - 3 \mathbf { c }}$ were spread over a water surface at room temperature to measure surface pressure $(\pi)$-area $(A)$ isotherms (Fig. 1). The isotherms show a gradual transition, indicating a slight structural alteration in the monolayer structure of the molecules. The $\pi-A$ isotherms of catalysts $\mathbf{2 a}-\mathbf{2} \mathbf{c}$ and $\mathbf{3 a} \mathbf{a}-\mathbf{3 c}$ clearly show high collapse pressure, suggesting the formation of a 
Table 4

Suzuki coupling of aryl halides with phenylboronic acid using $\mathbf{2} \mathbf{b}$ as a catalyst.

\begin{tabular}{|c|c|c|c|}
\hline Entry & Aryl halide & Product & Yield a (\%) \\
\hline 1 & $p-\mathrm{CH}_{3}-\mathrm{C}_{6} \mathrm{H}_{4} \mathrm{Br}$ & & $>99$ \\
\hline 2 & $p-\mathrm{CH}_{3} \mathrm{O}-\mathrm{C}_{6} \mathrm{H}_{4} \mathrm{Br}$ & & 99 \\
\hline 3 & $p-\mathrm{CF}_{3}-\mathrm{C}_{6} \mathrm{H}_{4} \mathrm{Br}$ & & 98 \\
\hline 4 & $p-\mathrm{NH}_{2}-\mathrm{C}_{6} \mathrm{H}_{4} \mathrm{Br}$ & & 82 \\
\hline 5 & $p-\mathrm{NO}_{2}-\mathrm{C}_{6} \mathrm{H}_{4} \mathrm{Br}$ & & $>99$ \\
\hline 6 & 1-bromonaphthalene & & 97 \\
\hline 7 & 3-bromo-pyridine & & 77 \\
\hline 8 & $o-\mathrm{CH}_{3}-\mathrm{C}_{6} \mathrm{H}_{4} \mathrm{Br}$ & & 85 \\
\hline 9 & $o-\mathrm{CN}-\mathrm{C}_{6} \mathrm{H}_{4} \mathrm{Br}$ & & 99 \\
\hline 10 & $m-\mathrm{CN}-\mathrm{C}_{6} \mathrm{H}_{4} \mathrm{Br}$ & & 99 \\
\hline 11 & $p-\mathrm{CN}-\mathrm{C}_{6} \mathrm{H}_{4} \mathrm{Br}$ & & 99 \\
\hline
\end{tabular}

Reaction conditions: ArX $0.5 \mathrm{mmol}, \mathrm{PhB}(\mathrm{OH})_{2} 0.6 \mathrm{mmol}, \mathrm{NaOH} 1.0$ mmol, catalyst 2b 0.001 mol\%, ethanol-water (2:1) $3 \mathrm{ml}$, rt.

a Determined by GC.

subphase of the condensed monolayers. Monolayers of $\mathbf{2 b}$ could be transferred onto hydrophilic or hydrophobic glass slides as a Z-type film with a transfer ratio of almost unity under surface pressure of $20 \mathrm{mN} / \mathrm{m}$ using Langmuir-Blodgett technique, indicating that the LB films were stable and uniform. An isotherm of $\mathbf{2} \mathbf{b}$ showed an increase in surface pressure near a mean molecular area of $65 \AA^{2} /$ molecule. This indicates that the content of catalyst in the LB films was $\sim 1 \times 10^{-5} \mathrm{~mol} \%$.

AFM was used to study the topography of the LB films and confirm the homogeneity and quality of the films transferred onto mica substrates. The AFM images of the LB films formed from complex $\mathbf{2 b}$ are shown in Fig. 2. The AFM image obtained after the hydrophilic treatment (Fig. 2(a)) does not show any sign of cluster formation and exhibits a low root mean square surface roughness ( $R_{\mathrm{RMS}}$ ) of $0.40 \mathrm{~nm}$. After the assembly of complex $\mathbf{2 b}$, clusters appear with increasing density as the number of layers increases. This results in an increase of $R_{\mathrm{RMS}}$ to $0.84,1.01$, and $2.92 \mathrm{~nm}$ for 1,5 , and 10 layers, respectively (Fig. 2(b)-(d)). This indicates that the LB films were successfully transferred onto the solid substrates.

We investigated the activity of LB films of complex $\mathbf{2 b}$ in a

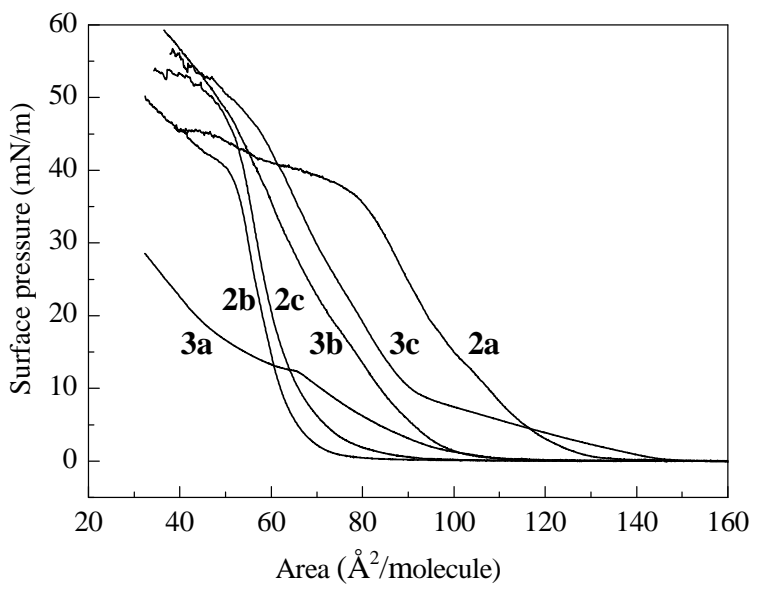

Fig. 1. $\pi$ - $A$ isotherms for $\mathbf{2 a - 2 c}$ and $\mathbf{3 a - 3} \mathbf{c}$ on pure water subphase. Compression rate: $20 \mathrm{mN} / \mathrm{m}$.

Suzuki reaction between 4-bromotoluene and phenylboronic acid using the optimized conditions used previously in the heterogeneous systems. The films exhibited high catalytic activity and the yields increased with the number of LB layers (Table 5, entries 1-4). The LB films also exhibited high catalytic activity in water (entry 5). To confirm that the catalysis was indeed heterogeneous, an auxiliary catalytic experiment was added. The catalyst $\mathbf{2 b}$ LB films were removed after $\sim 40 \%$ conversion. The reaction mixture was then allowed to continue without the catalyst film, and no further conversion was observed in the following $36 \mathrm{~h}$, strongly suggesting that catalyst did not dissolve into solution from the substrate and that the reaction was heterogeneous. The heterogeneous catalyst LB films of $\mathbf{2 b}$ obtained about 25 times more active than its homogeneous coun-
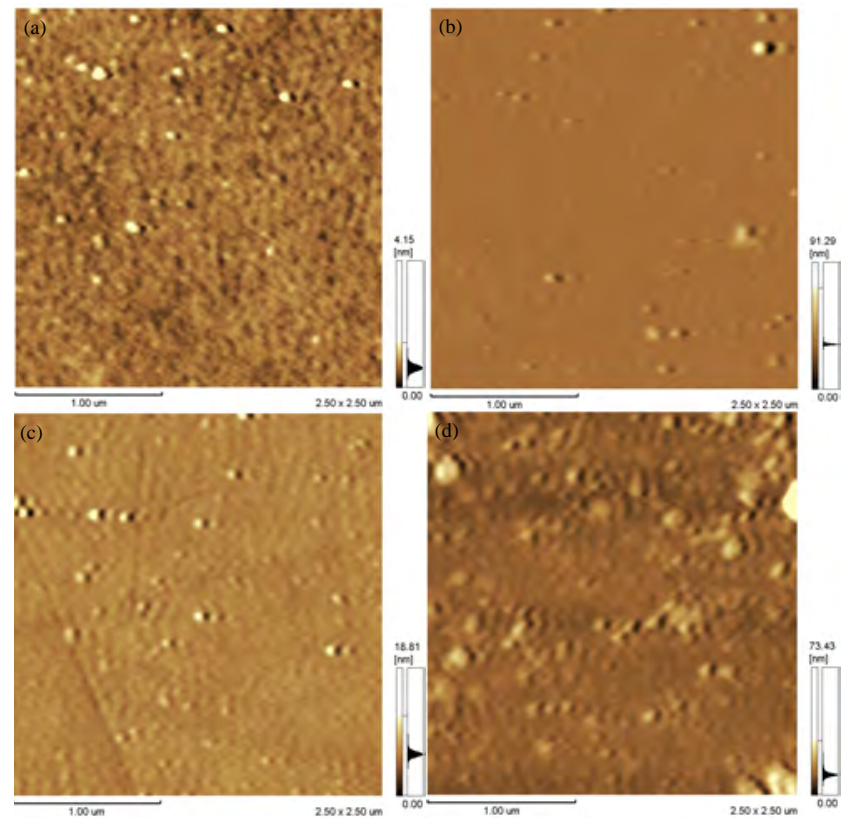

Fig. 2. AFM images of the silicon wafers after hydrophilic treatment (a), 1-layer (b), 5-layers (c), and 10-layers (d) LB films of complex 2b formed at surface pressure of $20 \mathrm{mN} / \mathrm{m}$. All the scan ranges were $2.5 \times$ $2.5 \mu \mathrm{m}^{2}$. 
Table 5

Suzuki coupling of aryl halides with phenylboronic acid catalyzed by $\mathbf{2 b}$ LB films.

\begin{tabular}{lccc} 
& \\
Entry & $\begin{array}{c}\text { Catalyst content } \\
\left(10^{-5} \mathrm{~mol} \%\right)\end{array}$ & Layer & Yield $^{\mathrm{a}}(\%)$ \\
\hline 1 & 6.17 & 2 & 21 \\
2 & 12.34 & 4 & 58 \\
3 & 18.52 & 6 & 73 \\
4 & 24.69 & 6 & 87 \\
$5^{\text {b }}$ & 12.34 & 4 & 46 \\
\hline
\end{tabular}

Reaction conditions: 4-bromotoluene $0.1 \mathrm{mmol}, \mathrm{PhB}(\mathrm{OH})_{2} 0.12 \mathrm{mmol}$, $\mathrm{NaOH} 0.125 \mathrm{mmol}$, ethanol-water (2:1) $3 \mathrm{ml}$, rt, $48 \mathrm{~h}$, in weighing bottle $(15 \mathrm{~mm} \times 40 \mathrm{~mm})$.

a Determined by HPLC based on the products.

${ }^{\mathrm{b}} \mathrm{H}_{2} \mathrm{O} 3 \mathrm{ml}, 72 \mathrm{~h}, n$-Bu $4 \mathrm{NBr} 0.12 \mathrm{mmol}$.

terpart. The catalytic results clearly demonstrated that ordered structures have a major influence on catalytic reactions.

\section{Conclusions}

A series of novel amphiphilic aryl imines and their cyclopalladated complexes $(\mathbf{2 a - 2} \mathbf{c}$ and $\mathbf{3 a}-\mathbf{3} \mathbf{c})$ were synthesized and characterized by ${ }^{1} \mathrm{H}$ NMR, ${ }^{13} \mathrm{C}$ NMR, MS, IR, and elemental analysis. The palladacycles are thermally stable and insensitive to oxygen and moisture. The complexes exhibited good activity in the Heck reaction of aryl halides with styrene. Furthermore, they were also found to be very efficient for the Suzuki coupling of aryl bromides with phenylboronic acid. The catalyst $\mathbf{2 b}$ showed suitability for Langmuir monolayer and LB film formation on solid slides. The catalytic activity of the catalyst films for the Suzuki coupling reaction was also investigated. The LB films of the catalyst $\mathbf{2 b}$ show significantly higher homogeneous catalytic activity for the Suzuki reaction than the other catalysts. This may indicate that ordered structure has a major influence on a catalytic reaction. The reusability of the LB films and the catalytic mechanism will be investigated in future studies.

\section{References}

[1] Corbet J-P, Mignani G. Chem Rev, 2006, 106: 2651

[2] Dieterich F, Stang P J. Metal-Catalyzed Cross-Coupling Reactions. New York: Wiley-VCH, 1998

[3] Tsuji J. Palladium in Organic Synthesis. Berlin: Springer, 2005

[4] Littke A F, Fu G C. Angew Chem Int Ed, 2002, 41: 4176

[5] Dallas A S, Gothelf K V.J Org Chem, 2005, 70: 3321

[6] Hassan J, Sevignon M, Gozzi C, Schulz E, Lemaire M. Chem Rev, 2002, 102: 1359

[7] Cacchi S, Fabrizi G. Chem Rev, 2005, 105: 2873

[8] Zeni G, Larock R C. Chem Rev, 2006, 106: 4644

[9] Beletskaya I P, Kashin A N, Karlstedt N B, Mitin A V, Cheprakov A V, Kazankov G M. J Organomet Chem, 2001, 622: 89

[10] Alacid E, Alonso D A, Botella L, Nájera C, Pacheco M C. Chem Record, 2006, 6: 117

[11] Zim D, Gruber A S, Ebeling G, Dupont J, Monteiro A L. Org Lett, 2000, 2: 2881

[12] Botella L, Najera C.J Organomet Chem, 2002, 663: 46

[13] Herrmann W A, Böhm V P W, Reisinger C P. J Organomet Chem, 1999, 576: 23

[14] Beller M, Fischer H, Herrmann W A, Öfele K, Brossmer C. Angew Chem Int Ed, 1995, 34: 1848

[15] Ohff M, Ohff A, Milstein D. Chem Commun, 1999: 357

[16] Weissman H, Milstein D. Chem Commun, 1999: 1901

[17] Ren G R, Cui X L, Yang E B, Yang F, Wu Y J. Tetrahedron, 2010, 66: 4022

[18] Leng Y T, Yang F, Wei K, Wu Y J. Tetrahedron, 2010, 66: 1244

[19] Huang M M, Feng Y J, Wu Y J. Tetrahedron, 2012, 68: 376

[20] Wei R, Li J, Zou D. J Organomet Chem, 2012, 68: 1351

[21] Töllner K, Popovitz-Biro R, Lahav M, Milstein D. Science, 1997, 278: 2100

[22] Abatti D, Zaniquelli M E D, Iamamoto Y, Idemori Y M. Thin Solid Films, 1997, 310: 296

[23] Benítez I O, Bujoli B, Camus L J, Lee C M, Odobel F, Talham D R. J Am Chem Soc, 2002, 124: 4363

[24] Park J Y, Zhang Y W, Grass M, Zhang T F, Somorjai G A. Nano Lett, 2008, 8: 673

[25] Mu B, Li T S, Li J Y, Wu Y J.J Organomet Chem, 2008, 693: 1243

[26] Mu B, Li T S, Li C H, Liu P P, Shang W, Wu Y J. Tetrahedron, 2009, 65: 2599

[27] Mu B, Li T S, Fu Z H, Wu Y J. Catal Commun, 2009, 10: 1497

\section{Graphical Abstract}

Chin. J. Catal., 2013, 34: 1583-1588 doi: 10.1016/S1872-2067(12)60613-5

Preparation, characterization and catalytic activity of amphiphilic cyclopalladated aryl imines and their Langmuir-Blodgett films

Na Zhao, Fei Wang, Meiling Zhou, Tiesheng Li*, Hui Liu, Wenjian Xu, Yangjie Wu*

Zhengzhou University

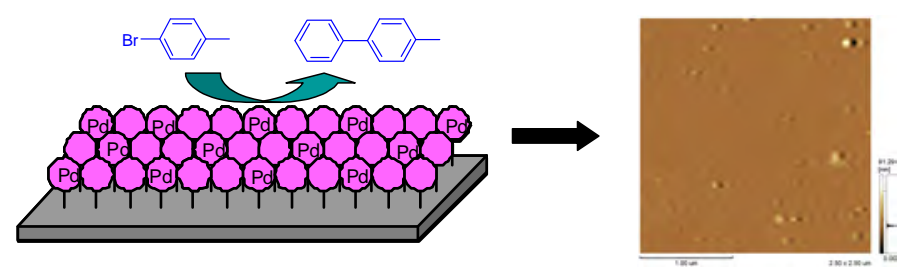

The amphiphilic cyclopalladated aryl imine catalysts were successfully transferred on the solid slides and can be used for the Suzuki reactions. 


\title{
两亲性芳香亚胺环钯化合物及其Langmuir-Blodgett膜的制备、表征及催化活性
}

\author{
赵 娜, 王飞, 周梅玲, 李铁生”, 刘 辉, 许文俭, 吴养洁 ${ }^{*}$
}

郑州大学化学与分子工程学院, 河南省化学生物与有机化学重点实验室, 郑州大学先进纳米信息材料实验室, 河南郑州450052

摘要: 合成并表征了一系列新型两亲性芳香亚胺环钯化合物. 结果显示, 该系列环钯催化剂可高效催化均相条件下的Heck和 Suzuki偶联反应. 将两亲性芳香亚胺环钯二聚体制成LB膜, 其在异相条件下的催化活性是均相条件下的25倍.

关键词: 芳香亚胺; 环钯催化剂; Langmuir-Blodgett膜; Suzuki反应; Heck反应

收稿日期: 2013-04-20. 接受日期: 2013-05-13. 出版日期: 2013-08-20.

*通讯联系人. 电子信箱: wyj@zzu.edu.cn

\#通讯联系人. 电子信箱: lts34@zzu.edu.cn

基金来源：国家自然科学基金(20973157); 郑州研究与发展基金(094SGZG23056).

本文的英文电子版由Elsevier出版社在ScienceDirect上出版(http://www.sciencedirect.com/science/journal/18722067). 